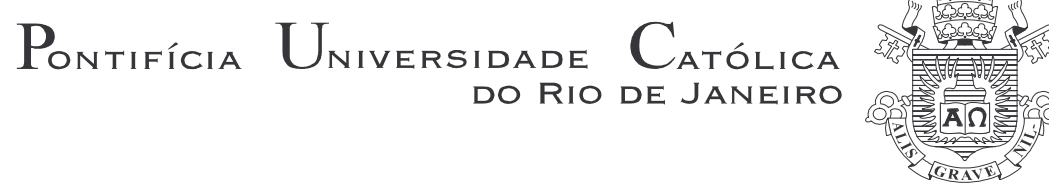

Maristela Rivera Tavares

Produção textual on-line: uma proposta de curso à luz de princípios sociointeracionistas

Dissertação apresentada ao Programa de PósGraduação em Estudos da Linguagem da PUC-Rio como requisito parcial para obtenção do título de Mestre em Estudos da Linguagem.

Orientadora: Profa. Dra. Tânia Mara Gastão Saliés

Rio de Janeiro

Março de 2006 


$$
\text { Pontifícia Universidade } \text { Cetólica }_{\text {Do Rio de Janeiro }}
$$

Maristela Rivera Tavares

\title{
Produção textual on-line: uma proposta de curso à luz de princípios sociointeracionistas
}

Dissertação de Mestrado

Dissertação apresentada como requisito parcial para obtenção do grau de Mestre pelo Programa de Pós-Graduação em Letras do Departamento de Letras do Centro de Teologia e Ciências Humanas da PUC-Rio. Aprovada pela Comissão Examinadora abaixo assinada.

\author{
Profa. Dra. Tânia Mara Gastão Saliés \\ Orientadora \\ Departamento de Letras - PUC-Rio
}

Profa. Dra. Kátia Cristina do Amaral Tavares Departamento de Letras - UFRJ

Profa. Dra. Maria Carmelita Padua Dias

Departamento de Letras - PUC-Rio

Prof. Paulo Fernando Carneiro de Andrade Coordenador Setorial do Centro de Teologia e Ciências Humanas - PUC-Rio

Rio de Janeiro, 08 de março de 2006. 
Todos os direitos reservados. É proibida a reprodução total ou parcial do trabalho sem autorização da universidade, da autora e da orientadora.

\section{Maristela Rivera Tavares}

Graduou-se em Letras na UERJ (Universidade do Estado do Rio de Janeiro) em 2003. Atuou como bolsista de docência durante a graduação, lecionando Língua Francesa no Licom/URRJ (Línguas para a Comunidade). Atua desde 2001 no FGV Online, programa de ensino a distância da Fundação Getulio Vargas, onde, atualmente, é Coordenadora Adjunta de Pós-Graduação e Graduação.

\section{Ficha Catalográfica}

Tavares, Maristela Rivera

Produção textual on-line: uma proposta de curso à luz de princípios sociointeracionais / Maristela Rivera Tavares ; orientadora: Tânia Mara Gastão Saliés. Rio de Janeiro : PUC, Departamento de Letras, 2006.

152 f. : il. ; $30 \mathrm{~cm}$

Dissertação (mestrado) - Pontifícia Universidade Católica do Rio de Janeiro, Departamento de Letras

Inclui bibliografia.

1. Letras - Teses. 2. EAD. 3. Produção de texto. 4. Práticas de linguagem. 5. Sociointeracionismo. I. Saliés, Tânia Mara Gastão. II. Pontifícia Universidade Católica do Rio de Janeiro. Departamento de Letras. III. Título. 


\section{Agradecimentos}

À minha orientadora, Profa. Tânia Saliés, que, em momento nenhum, desistiu de $\operatorname{mim}$.

Aos meus pais, responsáveis por tudo que realizo e que estão ao meu lado incondicionalmente.

Aos meus irmãos, que nunca deixam de acreditar em mim, nem mesmo quando eu não acredito mais.

Ao Miro, companheiro querido, amigo, colaborador e incentivador de sempre.

À Mary, eterna professora, grande amiga, "terrível” chefe, que me protege e me ama como mãe.

À Tati, que, prontamente, revisou meu trabalho e fez ricas sugestões.

À Chiquinha, por sua atenção e delicadeza do início ao fim do meu curso.

A todos os meus amigos, que me empurram para frente apenas por existirem na minha vida. 


\section{Resumo}

Tavares, Maristela Rivera; Saliés, Tânia Mara Gastão. Produção textual on-line: uma proposta de curso à luz de princípios sociointeracionistas. Rio de Janeiro, 2006. 152p. Dissertação de Mestrado - Departamento de Letras, Pontifícia Universidade Católica do Rio de Janeiro.

Esta pesquisa é um estudo teórico-exploratório sobre a modalidade de ensino a distância - EAD - via internet e sobre o processo de ensinoaprendizagem de produção de texto em língua materna "on-line". Algumas propostas de cursos de produção de texto existentes e oferecidos na internet foram criticamente analisadas, e se mostraram afastadas de práticas de linguagem que envolvem e privilegiam os pressupostos interacionais, uma vez que colocam a construção do sentido no texto, e não na interação. A partir do levantamento das necessidades e do perfil de um público-alvo selecionado, nossa proposta é planejar e elaborar um curso de produção de texto em língua materna a distância, via internet, que preencha as lacunas deixadas pelos cursos avaliados, ou seja, que privilegie não somente o conteúdo, mas principalmente a interação entre os participantes, a retextualização da "oralidade" para a escrita, o dialogismo e outras práticas de linguagem sociointeracionalmente ancoradas. Para tal, revisamos a literatura em EAD e ensino-aprendizagem de produção de textos, analisamos cursos existentes e fizemos pesquisa de campo com uma turma de produção de texto do curso de Letras da PUC-Rio. Os dados da análise de necessidades foram obtidos via observação em sala de aula, entrevista com a professora e questionário.

\section{Palavras-chave}

EAD, produção de texto, práticas de linguagem, sociointeracionismo. 


\section{Abstract}

Tavares, Maristela Rivera; Saliés, Tânia Mara Gastão (Advisor). On-line textual production: a course design in the light of socio-interactional principles. Rio de Janeiro, 2006. 152p. MSc. Dissertation - Departamento de Letras, Pontifícia Universidade Católica do Rio de Janeiro.

This research is a theoretical-exploratory study of e-learning and the teaching and learning of writing in the first language "on-line". A critical analysis of existing textual production courses offered in the internet have revealed negligence of language practices that involve interactional practices and that place meaning construction in interaction, rather than in the text. Based on a needs analysis and on the profile of the target group, the purpose of this study is to plan and design an on-line textual production course in L1 that would fill such gap and that would focus not only on content, but on language practices embodied by socio-interactional principles such as retextualization from orality to writing and dialogism. To do so, it reviews the literature on e-learning and the teachinglearning of writing, analyzes existing on-line writing courses, and conducts field research by observing and collecting data from a class of text production at PUCRio, majoring in Letters. The data for the needs analysis were gathered by means in class observation, interview with the professor, and one questionnaire.

\section{Keywords}

E-learning, textual production, language practices, socio-interactionism. 


\section{Sumário}

1. Introdução

2. Teoria da linguagem 17

2.1 Como entendemos a construção do sentido? O Funcionalismo 17

2.2 Modalidades oral e escrita: como se conjugam na produção do texto 20 escrito?

2.2.1 Caracterização e interdependência 21

2.2.2 Retextualização: passagem do texto de uma modalidade para 23 outra

2.2.3 Contribuições da prática de retextualização 26

2.2.4 Linguagem e expressão em EAD 26

2.3 A co-construção de textos pela inter-ação 27

2.3.1 Concepção de linguagem e produção de textos 28

2.3.2 Polifonia de vozes, dialogismo e intertextualidade na produção 29 de textos

2.3.3 O papel da situação discursiva na produção de textos $\quad 30$

3. Ensino a distância - EAD 33

3.1 Conceituação e histórico $\quad 33$

3.2 Características do EAD $\quad 36$

$\begin{array}{ll}3.3 \text { Interação e interatividade no EAD } & 37\end{array}$

3.3.1 Sala de aula virtual: o papel do professor e o do aluno na 38 interação

3.3.2 Meios de interação entre alunos e professor $\quad 40$

3.3.3 Interatividade com o conteúdo $\quad 41$

3.4 Hipertextualidade e hipermodalidade $\quad 42$

$\begin{array}{ll}3.4 .1 \text { Hipertextualidade } & 42\end{array}$

3.4.2 Hipermodalidade 43

3.5 Gêneros textuais digitais como meios de interação em EAD 45

3.5.1 Gêneros textuais $\quad 46$

3.5.2 Gêneros textuais digitais $\quad 47$

3.5.2.1 "E-mail" 47

3.5.2.2 Fórum de discussões $\quad 49$

3.5.2.3 "Chat" 50

3.6 Regras de comportamento na internet 52

4. A pesquisa $\quad 54$

4.1 Natureza $\quad 54$

4.2 Contexto $\quad 55$

4.3 Objetivos $\quad 55$

4.3.1 Objetivos gerais $\quad 55$

4.3.2 Objetivo específico $\quad 56$

4.4 Banco de dados $\quad 56$ 
5. Os achados 58

5.1 Notas de campo e entrevistas $\quad 58$

5.1.1 Discussão: notas de campo e entrevistas $\quad 60$

5.2 Questionário etnográfico 61

5.2.1 Discussão: questionário etnográfico 68

5.3 Cursos oferecidos na internet $\quad 75$

5.3.1 Descrição $\quad 75$

$\begin{array}{ll}\text { 5.3.2 Análise crítica } & 77\end{array}$

6. Proposta de curso $\quad 79$

6.1 Introdução $\quad 79$

6.2 Desenho do curso $\quad 82$

7. Conclusão 143

$\begin{array}{ll}\text { Referências bibliográficas } & 145\end{array}$

$\begin{array}{ll}\text { Anexo A } & 150\end{array}$

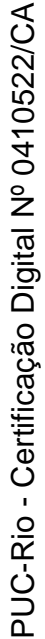




\section{Lista de tabelas}

Tabela 1 - Características do EAD 37

Tabela 2 - Conteúdo programático de Produção do Texto I 59

Tabela 3 - Perfil geral do público-alvo 63

Tabela 4 - Perfil escolar do público-alvo 64

Tabela 5 - Perfil escolar dos pais do público-alvo 65

Tabela 6 - Hábitos culturais $\quad 65$

Tabela 7 - Interesses - leitura e assuntos 66

Tabela 8 - Leitura anual $\quad 67$

Tabela 9 - Hábitos de lazer $\quad 67$

Tabela 10 - Acesso a computadores e à internet 68

Tabela 11 - Uso de computadores e da internet 68

Tabela 12 - Forma de trabalho preferida 69

Tabela 13 - Hábitos de produção de textos 69

Tabela 14 - Planejamento do curso $\quad 82$ 